\title{
Craniotomy site influences postoperative pain fol- lowing neurosurgical procedures: a retrospective study
}

\author{
[Le site de craniotomie influence la douleur postopératoire suite aux procédures \\ neurochirurgicales: une étude rétrospective]
}

Maxime Thibault BS, ${ }^{*}$ François Girard MD, ${ }^{*}$ Robert Moumdjian MD, $†$ Philippe Chouinard MD, ${ }^{*}$ Daniel Boudreault MD, ${ }^{*}$ Monique Ruel RN*

Objective: This retrospective study was designed to assess the intensity of postoperative pain in relation to the location of craniotomy.

Methods: After Research Ethics Board approval, data were collected from the charts of all patients who underwent a craniotomy at our institution between January 2004 and December 2005. The severity of post-craniotomy pain was assessed by collecting scores obtained using an II-point verbal rating scale and calculating the cumulative analgesic requirements for the first $48 \mathrm{hr}$ postoperatively. Data were compared according to the craniotomy location.

Results: Data from 299 patients was available for analysis. On average, $76 \%$ of patients experienced moderate to severe postoperative pain. Frontal craniotomy was associated with lower pain scores than four of six craniotomy sites analyzed, with $49 \%$ of patients reporting mild pain, a significant difference $(P<0.05)$ compared with all other groups except for parietal craniotomies. Frontal craniotomy patients also had lower opioid analgesic requirements compared to patients who underwent posterior fossa craniotomy $(P<0.05)$. Logistic regression analysis showed that craniotomy location $(P<0.000 \mathrm{I})$ and age $(P=0.004)$ were both independent predictors of the intensity of postoperative pain, with lower pain scores as age increased. Postoperative use of steroids, gender and presence of preoperative pain were not statistically linked to postoperative pain intensity. The prevalence of postoperative nausea and vomiting was $56 \%$ and it did not vary according to the location of craniotomy.

Conclusion: This study shows that the intensity of postoperative pain in neurosurgery is affected by the site of craniotomy. Frontal craniotomy patients experienced the lowest pain scores, and required significantly less opioid than patients undergoing posterior fossa interventions.
CAN J ANESTH 2007 / 54: 7 / pp 544-548

Objectif: Cette étude rétrospective a été conçue pour évaluer l'intensité de la douleur postopératoire par rapport au site de craniotomie.

Méthode : Avec l'accord du Comité d'éthique de la recherche, les données des dossiers de tous les patients ayant subi une craniotomie dans notre institution entre janvier 2004 et décembre 2005 ont été compilées. La sévérité de la douleur suite à la craniotomie $a$ été évaluée en récoltant les scores obtenus à l'aide d'une échelle d'évaluation verbale de II points et en calculant les besoins analgésiques cumulatifs pour les 48 heures suivant l'opération. Les données ont été comparées selon l'emplacement de la craniotomie.

Résultats : Les données de 299 patients étaient disponibles pour analyse. En moyenne, 76 \% des patients ont ressenti des douleurs postopératoires modérées à sévères. La craniotomie frontale était associée à des scores de douleur plus bas que quatre des six sites de craniotomie évalués, avec $49 \%$ des patients signalant une douleur légère, une différence significative $(P<0,05)$ comparée à tous les autres groupes hormis les craniotomies pariétales. Les patients ayant subi une craniotomie frontale présentaient également des besoins plus faibles en analgésiques opiacés par rapport aux patients ayant subi des craniotomies de la fosse postérieure $(P<0,05)$. Une analyse par régression logistique a montré que l'emplacement de la craniotomie $(P<0,00 I)$ ainsi que l'âge $(P$ $=0,004$ ) constituent tous deux des prédicteurs indépendants de l'intensité de la douleur postopératoire, les scores de douleur étant plus bas chez les patients plus âgés. L'utilisation postopératoire de stéroïdes, le sexe et la présence de douleur préopératoire n'étaient pas statistiquement associés à l'intensité de la douleur postopératoire. La prévalence de nausées et de vomissements postopératoires était de $56 \%$ et n'était pas affectée par le site de la craniotomie.

From the Department of Anesthesiology* and Neurosurgery Division, † Centre Hospitalier de l'Université de Montréal, Hôpital NotreDame, Montréal, Québec, Canada.

Address correspondence to: Dr. François Girard, Department of Anesthesiology, CHUM, Hôpital Notre-Dame, 1560 Sherbrooke East, Montréal, Québec H2L 4M1, Canada. Phone 514-890-8000, ext. 26876; Fax: 514-412-7653; E-mail: francois.girard.chum@ssss.gouv.qc.ca Accepted for publication March 13, 2007.

Revision accepted April 12, 2007. 
Conclusion : Cette étude démontre que l'intensité de la douleur postopératoire en neurochirurgie est affectée par le site de craniotomie. Les patients ayant subi une craniotomie frontale ont obtenu les scores de douleur les plus bas, et leurs besoins en opiacés ont été significativement moindres que chez les patients ayant subi des interventions sur la fosse postérieure.

S IXTY to $84 \%$ of patients experience moderate to severe pain following a craniotomy. ${ }^{1-3}$ Postcraniotomy pain is described as superficial in the majority of patients, suggesting a prominent role of pericranial muscles and soft tissue in its genesis. ${ }^{1}$ Observations from a few studies indicate, mainly as a secondary finding, that the severity of pain might be linked to the site of craniotomy. ${ }^{1-4}$

As the issue has not been clearly resolved, it is important to characterize the occurrence and severity of pain in relation to the location of craniotomy to improve clinical strategies to ensure optimal postoperative pain management of neurosurgical patients.

The aim of this study was to assess the intensity of postoperative pain according to the location of craniotomy. We hypothesized that certain types of craniotomy, namely those in which muscles are reflected, would be associated with more postoperative pain compared with other approaches. Pain scores and analgesic requirements for these patients should be higher compared with patients undergoing craniotomy at less painful sites. To test this hypothesis, we undertook a retrospective study over a two-year period that included patients who underwent a craniotomy in our institution. Secondarily, the incidence of postoperative nausea and vomiting (PONV) was evaluated.

\section{Methods}

Following approval of the institutional Research Ethics Board, we reviewed the charts of every patient who underwent a craniotomy at the CHUM, Hôpital Notre-Dame between January 2004 and December 2005. Five hundred and twenty-one charts were examined. Two hundred and twenty-two cases were excluded for the following reasons : prolonged postoperative intubation or impaired state of consciousness $(n=72)$, less than two verbal rating scale (VRS) scores available over the study period $(n=73)$, postoperative complications requiring a second procedure $(n=10)$, craniofacial surgery $(n=6)$, craniotomy associated with extensive cervical laminectomy $(n=$ $2)$, mini-craniotomy or enlarged burr hole $(n=7)$, postoperative pain not related to the cranial surgery $(n$
TABLE I Demographic data

\begin{tabular}{|c|c|c|c|c|}
\hline Craniotomy site & Patients (n) & Gender $M / F$ & Age (yr) & $\begin{array}{l}\text { ASA status } \\
\text { (median) }\end{array}$ \\
\hline Frontal & 68 & $37 / 31$ & $51 \pm 15$ & II \\
\hline $\begin{array}{l}\text { Fronto-temporal/ } \\
\text { pterional }\end{array}$ & 78 & $38 / 40$ & $48 \pm 14$ & II \\
\hline Temporal & 46 & $26 / 20$ & $51 \pm 15$ & II \\
\hline Parietal & 34 & $15 / 19$ & $52 \pm 15$ & II \\
\hline Occipital & 21 & $10 / 11$ & $55 \pm 14$ & II \\
\hline Posterior fossa & 52 & $21 / 31$ & $49 \pm 13$ & II \\
\hline
\end{tabular}

$=4)$, simultaneous craniotomies at two different sites $(n=2)$ and craniotomy incision encompassing more than one location (e.g., parieto-occipital) $(n=46)$.

Data were extracted directly from patients' charts and categorized into six groups according to the location of craniotomy: 1) frontal; 2) fronto-temporal/ pterional; 3) temporal; 4) parietal; 5) occipital; and 6) posterior fossa. The following patient's characteristics were collected: age, gender, ASA status, occurrence of preoperative headache and chronic (more than one week) treatment with analgesics and steroids.

At the CHUM, each time an analgesic is requested, patients rate their level of pain on an 11-point VRS, where 0 is defined as no pain at all, and 10 as the worst possible pain. Verbal rating scale scores are obtained and recorded in the chart by nurses trained with the technique. The following postoperative pain data were collected: median VRS scores for the first $48 \mathrm{hr}$ following surgery, cumulative dose of analgesics, and occurrence of PONV. The data were separated into three categories according to median VRS scores over the period of observation: mild pain (VRS scores of $1-$ 3 ), moderate pain (VRS scores of 3.5-7), and severe pain (VRS scores 7.5-10). To facilitate comparison, postoperatively administered opioid analgesics were converted into parenteral codeine equivalents (the most frequently used opioid in neurosurgery in our institution) using the conversion table from the DanaFarber Cancer Institute. ${ }^{5}$

Data were stored in an Excel ${ }^{\mathrm{TM}}$ database and the statistical analysis was performed with the SPSS version 15 statistical package (Chicago, IL, USA). Results are expressed as mean \pm SD or percentages except when stated otherwise. To detect a significant difference in pain scores according to the different craniotomy sites a one-way analysis of variance (ANOVA) was used. Differences between the craniotomy site groups were sought using the Person Chi-square test for large contingency tables (pain scores) and unpaired Student's 
$t$ test (total dosage of codeine) when appropriate. A logistic regression model was used to identify additional factors linked to the intensity of postoperative pain. Correlations between PONV and postoperative use of steroid and cumulative dose of codeine were tested using Spearman rank correlation coefficients. A $P<0.05$ was considered significant.

\section{Results}

The data from 299 patients were available for analysis. There were no demographic differences between patients when analyzed according to the site of craniotomy (Table I). Table II details the postoperative pain data according to the site of surgery. The overall incidence of mild pain was $24 \%, 51.5 \%$ for moderate pain, and $24.5 \%$ for severe pain. There was a significant relationship between the severity of pain and the different craniotomy sites (ANOVA, $P<0.0001$ ). Frontal craniotomy was associated with lower pain scores compared to other craniotomy sites (with the exception of parietal craniotomy) with $49 \%$ of patients experiencing mild pain (VRS $1-3$ ). The cumulative dose of codeine equivalents following a frontal craniotomy $(453 \pm 417 \mathrm{mg})$ was significantly lower $(P<$ $0.05)$ compared with the posterior fossa craniotomy $(816 \pm 697 \mathrm{mg})$.

In addition to the craniotomy location, the presence of preoperative pain, postoperative use of ste- roids, gender, and age were entered into a logistic regression model. Postoperative pain was dichotomized in the following manner for this model: mild pain (VRS 1-3) and moderate pain (VRS 3.5-10). Only craniotomy site $(P<0.0001)$ and age $(P=$ 0.004 ) remained as independent predictors of postoperative pain. Increased age was associated with lower pain scores in this model.

The overall incidence of PONV in the first 24 hr after surgery was $56 \%$. No interaction was found between the site of craniotomy and the occurrence of PONV. However, the postoperative use of steroids and the cumulative dose of codeine were correlated with PONV $(\mathrm{r}=-0.93, P=0.017$ and $\mathrm{r}=0.89, P=$ 0.03 , respectively).

\section{Discussion}

This study demonstrates that the site of craniotomy is a primary determinant of the severity of postoperative pain in neurosurgery. In general, frontal craniotomy was associated with lower pain scores than most other approaches, and a significantly lower consumption of opioid analgesics than posterior fossa craniotomy. The overall prevalence of moderate to severe pain was $76 \%$ for the first $48 \mathrm{hr}$ postoperative in the present study, with $56 \%$ of patients suffering from PONV.

Few studies have adequately assessed the incidence and intensity of pain following a craniotomy. As a sec-

TABLE II Postoperative pain data

\begin{tabular}{|c|c|c|c|c|c|c|}
\hline Craniotomy site & Patients (n) & $\begin{array}{l}\text { Mild } \\
(\text { VRS 1-3) } \\
(n, \%)\end{array}$ & $\begin{array}{l}\text { tensity of pain } \\
\text { Moderate } \\
\text { (VRS 3.5-7) } \\
(n, \%)\end{array}$ & $\begin{array}{l}\text { Severe } \\
(\operatorname{VRS}>7) \\
(n, \%)\end{array}$ & \multicolumn{2}{|c|}{$\begin{array}{l}\text { Cumulative dose of } \\
\text { codeine at } 48 \mathrm{hr}(\mathrm{mg})\end{array}$} \\
\hline Frontal * & 68 & $33(49)$ & $22(32)$ & $13(19)$ & \multicolumn{2}{|l|}{$453 \pm 417 \dagger$} \\
\hline Fronto-temporal/pterional & 78 & $12(15)$ & $46(59)$ & $20(26)$ & \multicolumn{2}{|l|}{$657 \pm 630$} \\
\hline Temporal & 46 & $4(9)$ & $31(67)$ & $11(24)$ & \multicolumn{2}{|l|}{$603 \pm 448$} \\
\hline Parietal & 34 & $12(32)$ & $17(50)$ & $8(24)$ & \multicolumn{2}{|l|}{$530 \pm 676$} \\
\hline Occipital & 21 & $5(24)$ & $13(62)$ & $3(14)$ & \multicolumn{2}{|l|}{$446 \pm 362$} \\
\hline Posterior fossa & 52 & $8(15.0)$ & $25(48)$ & $19(37)$ & \multicolumn{2}{|c|}{$816 \pm 697$} \\
\hline \multicolumn{7}{|c|}{$\begin{array}{l}\text { VRS }=\text { verbal rating scale. }{ }^{*} P<0.05 \text { frontal } v s \text { fronto-temporal/pterional, temporal, occipital, and posterior fossa; } \dagger P<0.05 \text { frontal } v s \\
\text { posterior fossa. }\end{array}$} \\
\hline \multicolumn{7}{|c|}{ TABLE III Perioperative data $(\%)$} \\
\hline Craniotomy site & Patients (n) & Preoperative pain & $\begin{array}{l}\text { Preoperative use } \\
\text { of analgesics }\end{array}$ & $\begin{array}{l}\text { Steroids } \\
\text { preoperatively }\end{array}$ & $\begin{array}{l}\text { Steroids } \\
\text { postoperatively }\end{array}$ & PONV \\
\hline Frontal & 68 & 37 & 19 & 39 & 73 & 53 \\
\hline Fronto-temporal/pterional & 78 & 29 & 18 & 10 & $24^{*}$ & 70 \\
\hline Temporal & 46 & 46 & 33 & 29 & 48 & 58 \\
\hline Parietal & 34 & 22 & 14 & 38 & 73 & 43 \\
\hline Occipital & 21 & 46 & 36 & 46 & 86 & 32 \\
\hline Posterior fossa & 52 & 36 & 26 & 24 & 60 & 59 \\
\hline
\end{tabular}

PONV $=$ postoperative nausea and vomiting; ${ }^{*} P<0.05$ compared to other craniotomy sites. 
ondary finding, some authors have suggested that the intensity of postoperative pain might be linked to craniotomy location. In a prospective study of 37 postcraniotomy patients, De Benedittis et al. ${ }^{1}$ observed a trend towards higher pain scores for suboccipital (seven patients) and subtemporal (nine patients) approaches. The authors speculated that a higher incidence of severe pain may result from muscle and tissue damage. Similar trends were reported in a prospective study that included 52 neurosurgical patients: temporal and occipital craniotomies were associated with a higher frequency of excruciating pain. ${ }^{3}$ Finally, Irefin et al. ${ }^{4}$ compared the intensity of pain in the immediate postoperative period (first two hours) in patients undergoing infratentorial craniotomy $(n=28)$ vs supratentorial craniotomy $(n=53)$. Again, a trend towards higher pain scores in the infratentorial group was obtained. Due to their limited sample size, none of these studies was definitive. Recognizing this limitation, the suggestion that temporal and suboccipital approaches may be associated with more postoperative pain than other craniotomy locations has important clinical implications.

With a substantially larger sample size, even considering the limitations of a retrospective study design, we were able to demonstrate a more specific effect of craniotomy location on the degree of postoperative pain experienced by neurosurgical patients than previous studies. Our results suggest that the severity of post-craniotomy pain is influenced more by muscle reflection, than by manipulation of the brain and meningeal tissues. Therefore, the relationship between the location of the craniotomy and the intensity of pain can be explained, at least in part, by the anatomical location of the pericranial muscles underlying the scalp incision. Occipital and posterior fossa approaches lead to a high intensity of pain possibly because of surgical retraction and the resulting postoperative spasm of an important muscle mass. Similarly, craniotomies involving reflection of the temporalis muscle (frontotemporal/pterional and temporal) are associated with a high prevalence of patients experiencing moderate to severe pain. In contrast, the less painful frontal craniotomy is associated with reduced muscular damage. This explanation also applies to parietal craniotomies (32\% incidence of mild pain) in which only periosteum rather than muscle is incised and reflected. ${ }^{3}$

As indicated in the logistic regression model, the preoperative presence of pain did not appear to influence the severity of postoperative pain in this study. Similarly, there was no difference in the preoperative use of analgesics between frontal craniotomy and other locations. The perioperative use of steroids was less frequent for fronto-temporal/pterional patients. This finding is not surprising since more than half of these patients $(43 / 78)$ underwent surgery for aneurysm clipping. The incidence of moderate to severe postoperative pain for aneurysm patients $(86 \%)$ was similar to that of others who underwent fronto-temporal craniotomy.

Many authors consider the use of codeine phosphate, a prodrug not completely metabolized by a portion of the population, to be inadequate as the first-line analgesic in neurosurgery. ${ }^{3,6-8}$ Codeine is widely used on our neurosurgical ward and although the $75 \%$ overall prevalence of moderate to severe pain is within the 60 to $84 \%$ reported by others, ${ }^{1-3}$ the present study certainly reinforces the concern that a more potent analgesic needs to be used in this surgical population.

The overall prevalence of PONV was $56 \%$ for the first $24 \mathrm{hr}$ postoperatively, which is similar to the results of another retrospective analysis, in which 50\% of patients had symptoms of nausea over the first 48 hr after craniotomy. ${ }^{9}$ However, in contrast with the results of this study showing a greater prevalence of PONV following infratentorial craniotomy, we found no such difference when comparing the different sites of craniotomy. In this regard, our results are in agreement with other studies that report no interaction between PONV and craniotomy location. ${ }^{3,4}$ The fact that PONV is negatively correlated with the postoperative use of steroids in this study goes along with recent evidence in the literature showing that dexamethasone administration reduces the risk of PONV by about $26 \%{ }^{10}$

The present study has several limitations. Because of its retrospective nature, pain scores were not recorded by the same individual and at fully standardized time intervals. However, in our institution, every nurse receives continuous training in pain management, including methods of evaluation using the VRS. In addition, to reduce the influence of an eventual interindividual variability, we evaluated the median pain score over the entire study period. A bias could also have been introduced in our results by the exclusion of patients with an insufficient number of VRS scores in the medical chart, and patients who had craniotomy over different locations.

In conclusion, this study shows that the intensity of postoperative pain in neurosurgery is affected by the craniotomy site. Frontal craniotomy was associated with lower pain scores and lower analgesic requirements than posterior fossa craniotomy. The $76 \%$ overall prevalence of patients experiencing moderate to severe pain strengthens the importance of implement- 
ing new techniques to manage postoperative pain in neurosurgery. Future studies will need to consider the influence of craniotomy site on postoperative pain.

\section{References}

1 De Benedittis G, Lorenzetti A, Migliore M, Spagnoli D, Tiberio F, Villani RM. Postoperative pain in neurosurgery: a pilot study in brain surgery. Neurosurgery 1996; 38: 466-70.

2 Nguyen A, Girard F, Boudreault D, et al. Scalp nerve blocks decreases the severity of pain after craniotomy. Anesth Analg 2001; 93: 1272-6.

3 Quiney N, Cooper R, Stoneham M, Walters F. Pain after craniotomy. A time for reappraisal? Br J Neurosurg 1996; 10: 295-9.

4 Irefin $S A$, Schubert A, Bloomfield EL, DeBoer GE, Mascha EJ, Ebrahim ZY. The effect of craniotomy location on postoperative pain and nausea. J Anesth 2003; 17: 227-31.

5 Foley KM. The treatment of cancer pain. N Engl J Med 1985; 313: 84-95.

6 Goldsack C, Souplak SM, Smith M. A double-blind comparison of codeine and morphine for postoperative analgesia following intracranial surgery. Anaesthesia 1996; 51: 1029-32.

7 Stoneham MD, Walters FJ. Post-operative analgesia for craniotomy patients: current attitudes among neuroanaesthetists. Eur J Anaesthesiol 1995; 12: 571-5.

8 Stoneham MD, Cooper R, Quiney NF, Walters FJ. Pain following craniotomy: a preliminary study comparing PCA morphine with intramuscular codeine phosphate. Anaesthesia 1996; 51: 1176-8.

9 Fabling JM, Gan TJ, Guy J, Borel CO, el-Moalem HE, Warner DS. Postoperative nausea and vomiting. A retrospective analysis in patients undergoing elective craniotomy. J Neurosurg Anesthesiol 1997; 9: 308-12.

10 Apfel CC, Korttila K, Abdalla M, et al. A factorial trial of six interventions for the prevention of postoperative nausea and vomiting. N Engl J Med 2004; 350: 2441-51. 